\title{
Poly(phenylenediamine): An effective polymer motif for anticorrosive applications
}

\author{
C. Verma and M.A. Quraishi ${ }^{(1) *}$ \\ Interdisciplinary Research Center for Advanced Materials, King Fahd University \\ of Petroleum and Minerals, Dhahran, 31261, Saudi Arabia \\ *E-mail: cbverma38@gmail.com, chandraverma.rs.apc@itbhu.ac.in
}

\begin{abstract}
Phenylenediamine $\left(\mathrm{C}_{6} \mathrm{H}_{4}\left(\mathrm{NH}_{2}\right)_{2}\right)$ exists in three isomeric forms i.e. ortho-isomer (PoPD), metaisomer (PmPD) and para-isomer (PpPD). The $o$-phenylenediamine, $m$-phenylenediamine and $p$-phenylenediamine polymerized to give poly(o-phenylenediamine) (PoPD), poly $(m$ phenylenediamine) (PmPD) and poly( $p$-phenylenediamine) (PpPD), respectively. Literature investigation suggests that poly(phenylenediamines), specially poly(o-phenylenediamine) are widely employed as anticorrosive materials for different metals and alloys, especially in the sodium chloride and hydrochloric acid solutions. Because of their polymeric nature, PoPD, PmPD and PpPD provide excellent surface protection and exhibit excellent anticorrosive activity. They are extensively used as anticorrosive materials for different metals and alloys such as mild steel, carbon steel, aluminum, copper zinc etc. in different common electrolytes including sulfuric acid and hydrochloric acid. PoPD, PmPD and PpPD can interact with metal surface using their non-bonding electrons of nitrogen atoms and $\pi$-electrons of aromatic rings. Due to the presence of various electron rich adsorption sites, PoPD, PmPD and PpPD and their derivatives are expected to form a compact anticorrosive film on the metal surface. Their adsorption on metallic surface mostly follows the Langmuir adsorption isotherm model. Present review describes the assortment of present and past advancements on anticorrosive effect of PoPD, PmPD and PpPD. This article also aims to describe the corrosion inhibition mechanism of metals and alloys using PoPD, PmPD and PpPD.
\end{abstract}

Received: March 30, 2021. Published: June 28, 2021

doi: $\underline{10.17675 / 2305-6894-2021-10-3-1}$

Keywords: poly(o-phenylenediamine), anticorrosive material, polymer corrosion inhibitors, surface protection and mixed-type.

\section{Introduction}

\subsection{Advantages of polymers over traditional corrosion inhibitors}

Varying upon the nature of environment and metal, numerous corrosion monitoring practices have been adopted [1-3]. Among them, use of organic corrosion inhibitors is still one of the best corrosion monitoring strategies [4-7]. Obviously, they adsorb and form an inherent and compact anticorrosive film. Presence of multiple bonds and polar substituents play a significant role in the adsorption process [8-11]. These electron rich sites donate their 
electrons into d-orbital of the metal through coordination bonds. Nevertheless, anticorrosive application of the traditional organic compounds is limited because of the insufficient surface protection. Due to their molecular nature, traditional organic corrosion inhibitors don't provide sufficient magnitude of surface coverage. More so, they contain comparatively lesser number of adsorption sites. Therefore, application of polymers of the traditional corrosion inhibitors having larger molecular size and greater number of adsorption sites is acquiring meticulous interest $[8,12-15]$. Replacement of traditional organic corrosion inhibitors acquires following advantages:

a. Larger molecular size: Polymers are formed by the polymerization of simple organic molecules (called as monomers) where thousands of molecules combine together. Polymers acquire larger molecular size and therefore provide excellent surface coverage.

b. Greater number of adsorption sites: Because of the repetition of monomer units in polymers, number of adsorption sites gets magnified.

c. Greater surface coverage and protection: As compared to the traditional corrosion inhibitors, polymer based anticorrosive materials provide greater surface coverage and protection,

d. Ease of synthesis: Obviously, synthesis of polymers would be relatively eased, costeffective and eco-friendly because of the one step polymerization reaction unlike to multi step synthesis of traditional organic corrosion inhibitors.

e. Natural availability: There are a large number of natural polymers such as chitosan, cellulose, natural gums, chitin and latex etc. that can be used at the place of traditional toxic and non-environmental friendly organic corrosion inhibitors. Because of their natural origin, most of the natural polymers are biotolerable and biodegradable.

f. Useful at high temperature: Some of the polymers can be used as anticorrosive materials at high temperature. Generally, application of traditional corrosion inhibitors is limited because of their degradation at high temperature.

g. Useful in highly aggressive electrolyte: Some of the polymers can be used as anticorrosive materials in highly aggressive electrolytes including 5-28\% of acidic solutions. Generally, application of traditional corrosion inhibitors is limited because of their degradation, rearrangement or fragmentation at high electrolyte concentration.

\subsection{Poly(o-phenylenediamine): Basics and anticorrosive applications}

Phenylenediamine (PPD) is an organic species with molecular formula of $\mathrm{C}_{6} \mathrm{H}_{4}\left(\mathrm{NH}_{2}\right)_{2}$. This can be treated as an amino $\left(-\mathrm{NH}_{2}\right)$ substituted derivative of aniline. Phenylenediamine exists in three isomeric forms depending upon the relative position of two amino groups in the aromatic ring. Obviously, their polymerization gives three types of phenylenediamine polymers, namely, poly (o-phenylenediamine) (PoPD), poly ( $m$-phenylenediamine) (PmPD) and $\operatorname{poly}(p$-phenylenediamine) (PpPD). Chemical structures of $o$-phenylenediamine, $m$ phenylenediamine and $p$-phenylenediamine and their respective polymers are presented in Table 1. Literature investigation shows that poly(o-phenylenediamine) (PoPD), $\operatorname{poly}(m-$ 
phenylenediamine) (PmPD) and poly(p-phenylenediamine) (PpPD) are evaluated as corrosion inhibitors in aqueous as well as coating phases [16-19].

Table 1. Chemical structures of $o$-Phenylenediamine, $m$-Phenylenediamine and $p$-Phenylenediamine and their respective polymers.

\# Name and structure

of phenylenediamine

Name and structure of polymer

(-Phenylenediamine

\section{Literature survey: Poly(phenylenediamines) as corrosion inhibitors}

\subsection{Poly(phenylenediamines) as aqueous phase corrosion inhibitors}

Although poly(phenylenediamine) is insoluble in water because of its polymeric behavior, in acidic solutions its nitrogen can undergo protonation and make poly(phenylenediamine) soluble in polar aqueous electrolytes. After getting dissolved, poly(phenylenediamine) may interact with a metallic surface using the unshared electron pairs of nitrogen atoms and $\pi$ electrons of various double bonds. Therefore, in aqueous electrolytes, poly(phenylenediamine) forms a protective film through its adsorption at the interface of metal and electrolyte. Literature study suggests that poly( $p$-phenylenediamine) (PoPD) and poly $(o-$ phenylenediamine) (PoPD) are tested for their anticorrosive properties in a few reports [2022]. These compounds show reasonable good anticorrosive potential at relatively low concentration. Mostly, these compounds become effective by adsorbing at the interface of metal and electrolyte following through Langmuir adsorption isotherm. Using 
potentiodynamic polarization study it was derived that compounds act as mixed-type corrosion inhibitors with some anodic predominance in report.

Using PDP method, Rehim et al. [3] showed that the presence of poly(o-phenylenediamine) (PoPD) in the corrosive medium adversely affects mild steel corrosion in $1 \mathrm{M} \mathrm{HCl}$ solution. Moreover, this decrease in corrosion rate was consistent with poly $(o-$ phenylenediamine) (PoPD) concentration. PoPD exhibits the highest inhibition effectiveness of $95 \%$ at as low as $15 \mathrm{ppm}$ concentration. These authors also observed that an increase in temperature results in a subsequent increase in the corrosion rate. A summary of reports on poly(phenylenediamines) as aqueous phase corrosion inhibitors is given in Table 2 .

Table 2. Summary of reports on poly(phenylenediamine) as aqueous phase corrosion inhibitors.

\begin{tabular}{|c|c|c|c|c|c|}
\hline$\#$ & $\begin{array}{c}\text { Name and } \\
\text { abbreviation }\end{array}$ & Electrolyte & Metal/alloy & Salient features & Ref. \\
\hline 1 & $\begin{array}{c}\operatorname{Poly}(p- \\
\text { phenylenediamine }) \\
\text { (PoPD) }\end{array}$ & $1 \mathrm{M} \mathrm{HCl}$ & Iron alloy & $\begin{array}{l}\text { PpPD shows highest effectiveness of } \\
92.7 \% \text { at } 500 \text { ppm concentration. } \\
\text { PoPD acts as a mixed-type inhibitor } \\
\text { and its adsorption followed Langmuir } \\
\text { adsorption isotherm. }\end{array}$ & {$[20]$} \\
\hline 2 & $\begin{array}{c}\text { Poly }(\mathrm{p}- \\
\text { phenylenediamine }) \\
(\mathrm{PpPD})\end{array}$ & $1 \mathrm{M} \mathrm{HCl}$ & Mild steel & $\begin{array}{l}\text { PpPD shows highest efficiency of } \\
52 \% \text { at } 15 \text { ppm concentration. It acts } \\
\text { as mainly anodic-type corrosion } \\
\text { inhibitors and its adsorption followed } \\
\text { the Langmuir adsorption isotherm } \\
\text { model. }\end{array}$ & {$[21]$} \\
\hline 3 & $\begin{array}{c}\text { Poly(o- } \\
\text { phenylenediamine) } \\
\text { (PoPD) }\end{array}$ & $1 \mathrm{M} \mathrm{HCl}$ & Mild steel & $\begin{array}{l}\text { PoPD shows excellent corrosion } \\
\text { protection of } 95 \% \text { at } 15 \mathrm{ppm} \\
\text { concentration. It behaves as mixed- } \\
\text { type corrosion inhibitor and its } \\
\text { adsorption obeyed the Langmuir } \\
\text { adsorption isotherm. }\end{array}$ & {$[22]$} \\
\hline
\end{tabular}

\subsection{Poly(phenylenediamines) as coating phase corrosion inhibitors}

Because of its polymeric nature, poly(phenylenediamine) has strong ability to provide sufficient metallic surface coverage. Poly(phenylenediamines) possess numerous nonbonding electrons of nitrogen atoms and $\pi$-electron of double bonds $(>\mathrm{C}=\mathrm{C}<\&>\mathrm{C}=\mathrm{N}-$-) through which they easily get adsorbed on a metal surface and provide excellent corrosion protection. Literature study suggests that poly(phenylenediamine) and its composites are used as efficient anticorrosive coating materials for different metal/electrolyte combinations. Muthirulan et al. [23] reported the synthesis, characterization and corrosion inhibition potential evaluation of poly(o-phenylenediamine) nanofibers (PoPD) for 316L SS in $3.5 \%$ $\mathrm{NaCl}$ solution. The PoPD was synthesized using chemical oxidation polymerization method 
and it was characterized using FT-IR, TEM, SEM, and UV-vis spectroscopic methods. The corrosion inhibition potential of PoPD was tested using electrochemical impedance spectroscope (EIS) and potentiodynamic polarization methods. EIS analysis suggests that PoPD based anticorrosive coating exhibits $93 \%$. Corrosion inhibition potential of poly-ophenylenediamine (PoPD) based anticorrosive coatings have also been described elsewhere and summary of these reports are given in Table 3 [24-26].

Recently, application of poly(phenylenediamine) and carbon allotrope based composites as anticorrosive coating materials is gaining attention [27, 28]. Cui and coworkers [27], synthesized a poly(o-phenylenediamine) modified graphene (G-PoPD) and evaluated its inhibition performance of epoxy resin (EP) based anticorrosive coating for Q235 carbon steel in 3.5\% $\mathrm{NaCl}$ solution. It was derived that presence of poly $(o-$ phenylenediamine) modified graphene (G-PoPD) enhances the protection efficiency of EP because of combined anticorrosive barrier potential of $\mathrm{G}$ nanosheets and metallic surface passivation by PoPD nanoparticles. The PoPD nanoparticles were dispersed with graphene nanosheets after 30 minutes sonication in THF (tetrahydrofuran). Authors proposed that anticorrosive properties of composite based coatings are directly related with barrier property of coatings and the dispersion ability of nanofillers inside the polymer matrixes. Using electrochemical methods it is derived that presence of graphene nanosheets greatly improved the anticorrosive property of EP based coating. Similarly, in another report [28], corrosion inhibition potential of poly( o-phenylenediamine)@ multi-walled carbon nanotubes (PoPDA@MWCNTs) coating was evaluated for 316L stainless steel in 3.5\% NaCl solution. The relative corrosion inhibition potential of different formulations followed the order: PoPDA $\left(0.562 \mu \mathrm{A} \cdot \mathrm{cm}^{-2}\right)<$ PoPDA@FMWCNTs $\left(0.28 \mu \mathrm{A} \mathrm{cm} \mathrm{cm}^{-2}\right)<$ PoPDA@MWCNTs $\left(0.12 \mu \mathrm{A} \cdot \mathrm{cm}^{-2}\right)$. Careful inspection of literature also suggests that poly $(o$-phenylenediamine)/ZnO composites are also evaluated as anticorrosive coating formulations for steel alloys in 3.5\% NaCl solution [29-31]. More so, amine-containing poly(o-phenylenediamine) (PoPD) [32] and poly(aniline-co-o-phenylenediamine) (Ani-co-oPD) [33] have also been tested as anticorrosive formulations of steel alloys in $\mathrm{NaCl}$ based electrolytes. A summary of reports on poly(phenylenediamine) as coating phase corrosion inhibitors is presented in Table 3.

Table 3. Summary of reports on poly(phenylenediamine) as coating corrosion phase inhibitors.

\begin{tabular}{|c|c|c|c|c|c|}
\hline \# & $\begin{array}{c}\text { Name and } \\
\text { abbreviation }\end{array}$ & Electrolyte & Metal/alloy & Salient features & Ref \\
\hline 1 & $\begin{array}{c}\operatorname{Poly}(o- \\
\text { phenylenediamine }) \\
\text { nanofibers (PoPD) }\end{array}$ & $3.5 \% \mathrm{NaCl}$ & 316L SS & $\begin{array}{l}\text { Characterization of PoPD was } \\
\text { carried out using TEM, SEM, UV- } \\
\text { vis and FT-IR. PoPD coating } \\
\text { exhibits } 93 \% \text { protection efficiency } \\
\text { as compared to the non-coated one. }\end{array}$ & {$[23]$} \\
\hline
\end{tabular}




\begin{tabular}{|c|c|c|c|c|c|}
\hline \# & $\begin{array}{l}\text { Name and } \\
\text { abbreviation }\end{array}$ & Electrolyte & Metal/alloy & Salient features & Ref. \\
\hline 2 & $\begin{array}{c}\text { Electropolymerized } \\
\text { poly- } O \text { - } \\
\text { phenylenediamine } \\
\text { (PoPD) }\end{array}$ & $\begin{array}{c}0.4 \mathrm{M} \\
\mathrm{HCl} / 0.1 \mathrm{M} \\
\mathrm{NaCl}\end{array}$ & $\begin{array}{c}304 \\
\text { Stainless } \\
\text { Steel }\end{array}$ & $\begin{array}{l}\text { PoPD based coating provide } \\
\text { excellent anticorrosive activity. }\end{array}$ & [24] \\
\hline 3 & $\begin{array}{c}\operatorname{Poly}(o- \\
\text { phenylenediamine }) \\
\text { (PoPD) }\end{array}$ & $0.5 \mathrm{M} \mathrm{HCl}$ & Mild steel & $\begin{array}{l}\text { PoPD was characterized using } \\
\text { SEM, FT-IR, AFM and UV-Vis } \\
\text { spectroscopy. The PoPD based } \\
\text { coating exhibits } 87.6 \% \text { inhibition } \\
\text { efficiency. }\end{array}$ & [25] \\
\hline 4 & $\begin{array}{c}\operatorname{Poly}(o- \\
\text { phenylenediamine }) \\
(\text { PoPD })\end{array}$ & $3.5 \% \mathrm{NaCl}$ & Mild steel & $\begin{array}{l}\text { PoPD was developed in various } \\
\text { acidic media and it was observed } \\
\text { that PoPD derived from different } \\
\text { acidic media followed the order: } \\
\text { PoPD-HNO } \mathrm{H}_{3}>\text { PoPD- } \mathrm{H}_{3} \mathrm{PO}_{4}> \\
\text { PoPD-HCl. }\end{array}$ & [26] \\
\hline 5 & $\begin{array}{c}\operatorname{Poly}(o- \\
\text { phenylenediamine }) \\
\text { modified graphene } \\
\text { (PoPD) }\end{array}$ & $3.5 \% \mathrm{NaCl}$ & $\begin{array}{l}\text { Q235 } \\
\text { Carbon } \\
\text { steel }\end{array}$ & $\begin{array}{c}\text { It was observed that PoPD } \\
\text { nanoparticles adsorb on steel } \\
\text { surface via } \pi-\pi \text { interactions. PoPD } \\
\text { coatings containing } 0.5-1.0 \% \mathrm{G} \\
\text { exhibit excellent anticorrosive } \\
\text { activity. }\end{array}$ & [27] \\
\hline 6 & $\begin{array}{c}\text { Poly }(o- \\
\text { phenylenediamine) @ } \\
\text { multi-walled carbon } \\
\text { nanotubes } \\
\text { (PoPDA @ MWCNTs) }\end{array}$ & $3.5 \% \mathrm{NaCl}$ & $\begin{array}{l}\text { 316L SS } \\
\text { (Stainless } \\
\text { steel) }\end{array}$ & $\begin{array}{c}\text { Decrease in corrosion current } \\
\text { densities of different coating } \\
\text { formulations followed the sequence: } \\
\text { PoPDA }\left(0.562 \mu \mathrm{A} \cdot \mathrm{cm}^{-2}\right)< \\
\text { PoPDA@ @MWCNTs } \\
\left(0.0 .28 \mu \mathrm{A} \cdot \mathrm{cm}^{-2}\right)< \\
\text { PoPDA@ } \mathrm{MWCNTs} \\
\left(0.0 .12 \mu \mathrm{A} \cdot \mathrm{cm}^{-2}\right) .\end{array}$ & [28] \\
\hline 7 & $\begin{array}{c}\text { Poly }(o- \\
\text { phenylenediamine })-\mathrm{ZnO} \\
\text { (PoPD-ZnO) composite }\end{array}$ & $3.5 \% \mathrm{NaCl}$ & $\begin{array}{l}\text { Stainless } \\
\text { steel }\end{array}$ & $\begin{array}{l}\text { Corrosion inhibition potential of } \\
\text { WPU, PoPD and PoPD-ZnO were } \\
\text { determined and their inhibition } \\
\text { efficiency followed the order: } \\
\text { PoPD-ZnO }(97.7 \%)>\text { PoPD } \\
(94.4 \%)>\text { WPU }(86.2 \%) \text {. ZnO } \\
\text { improves anticorrosive potential by } \\
\text { blocking the surface pores. }\end{array}$ & [29] \\
\hline
\end{tabular}




\begin{tabular}{|c|c|c|c|c|c|}
\hline \# & $\begin{array}{c}\text { Name and } \\
\text { abbreviation }\end{array}$ & Electrolyte & Metal/alloy & Salient features & Ref. \\
\hline 8 & $\begin{array}{c}\operatorname{Poly}(o- \\
\text { phenylenediamine }) / \mathrm{ZnO} \\
(\mathrm{PoPD} / \mathrm{ZnO}) \\
\text { nanocomposites }\end{array}$ & $3.5 \% \mathrm{NaCl}$ & $\begin{array}{c}304 \\
\text { Austenitic } \\
\text { stainless } \\
\text { steel (SS) }\end{array}$ & $\begin{array}{l}\text { PoPD and PoPD/ZnO were } \\
\text { electrodeposited on SS surface and } \\
\text { examined for their anticorrosive } \\
\text { activity. PoPD/ZnO based coating } \\
\text { exhibits high protection } \\
\text { effectiveness than that of the PoPD. }\end{array}$ & [30] \\
\hline 9 & $\begin{array}{c}\operatorname{Poly}(o- \\
\text { phenylenediamine })-\mathrm{ZnO} \\
\text { composites }\end{array}$ & $3.5 \% \mathrm{NaCl}$ & $\begin{array}{c}\text { Carbon } \\
\text { steel }\end{array}$ & $\begin{array}{l}\text { It was derived that PoPD-WPU } \\
\text { coating (PWC) and PoPD-ZnO- } \\
\text { WPU effectively improve the } \\
\text { anticorrosive potential of WPU } \\
\text { based coatings. }\end{array}$ & [31] \\
\hline 10 & $\begin{array}{l}\text { Amine-containing } \\
\text { poly }(o- \\
\text { phenylenediamine }) \\
\text { (PoPD) }\end{array}$ & $3.5 \% \mathrm{NaCl}$ & Q235 steel & $\begin{array}{l}0.5 \mathrm{wt} \%, 1.0 \mathrm{wt} \% \text { and } 2.0 \mathrm{wt} \% \text { of } \\
\text { PoPD was used in epoxy based } \\
\text { anticorrosive coatings. It was } \\
\text { derived that presence of PoPD } \\
\text { significantly enhances the } \\
\text { anticorrosive effectiveness of the } \\
\text { coating. Presence of } 0.5 \mathrm{wt} \% \text { of } \\
\text { PoPD (0.5-PDEP) causes highest } \\
\text { improvement in the protection } \\
\text { power. }\end{array}$ & [32] \\
\hline 11 & $\begin{array}{l}\text { Poly(aniline-co- } o \text { - } \\
\text { phenylenediamine) } \\
\text { (Ani-co-oPD) }\end{array}$ & $1 \% \mathrm{NaCl}$ & Steel alloy & $\begin{array}{c}\text { Ani-co-oPD behaves as a strong } \\
\text { anticorrosive material and exhibits } \\
\text { highest protection efficiency of } \\
78 \% \text {. }\end{array}$ & [33] \\
\hline
\end{tabular}

WPU: Waterborne polyurethane.

\section{Summary and outlook}

Present review article describes the collection on corrosion inhibition potential of $\operatorname{poly}(o-$ phenylenediamine) (PoPD), poly( $m$-phenylenediamine) (PmPD) and poly $(p$ phenylenediamine) (PpPD). Through the ongoing discussion it is clear that these polymers and their composites provide excellent surface protection because of the presence of numerous non-bonding electron pairs of nitrogen and $\pi$-electrons of double bonds $(>C=C<$ $\&>\mathrm{C}=\mathrm{N}-$ ). Through, these electron rich sites, poly(phenylenediamine) and its composites form coordination bonding with metallic atoms and adsorb effectively that results into the formation of anticorrosive protective film. Literature investigation suggests that poly(phenylenediamine) is also tested as aqueous phase corrosion inhibitor, especially for the steel alloys. Therefore, use of this polymer as a aqueous phase corrosion inhibitor for other metals and alloys such as aluminum, copper, zinc and their alloys should be evaluated. The poly(phenylenediamine) is used as a corrosion inhibitor only in hydrochloric acid 
solution therefore poly(phenylenediamine) and its composites should also be tested as corrosion inhibitor in other electrolytes including nitric acid, sulfuric acid and phosphoric acid. It can also be seen that poly (phenylenediamine) is tested as corrosion inhibitors in $1 \mathrm{M}$ $\mathrm{HCl}$ solution therefore implementation of poly(phenylenediamine) and its composites should also be explored for industrially useful electrolytes of higher concentrations. Literature investigation suggests that in coating phase, poly(phenylenediamine) and its composites are mostly used in sodium chloride based solution. Their implementation should also be explored in other electrolytes.

\section{References}

1. C.I. Ossai, Advances in asset management techniques: An overview of corrosion mechanisms and mitigation strategies for oil and gas pipelines, Int. Scholarly Res. Not., 2012, 570143, 1-10. doi: 10.5402/2012/570143

2. A.G. Fernández and L.F. Cabeza, Corrosion monitoring and mitigation techniques on advanced thermal energy storage materials for CSP plants, Sol. Energy Mater. Sol. Cells, 2019, 192, 179-187. doi: 10.1016/j.solmat.2018.12.028

3. J. Hu, P. Sui, S. Kumar and N. Djilali, Modelling and simulations of carbon corrosion during operation of a polymer electrolyte membrane fuel cell, Electrochim. Acta, 2009, 54, 5583-5592. doi: $10.1016 /$ j.electacta.2009.04.073

4. S.V. Lamaka, M.L. Zheludkevich, K. Yasakau, M. Montemor and M.G. Ferreira, High effective organic corrosion inhibitors for 2024 aluminium alloy, Electrochim. Acta, 2007, 52, 7231-7247. doi: 10.1016/j.electacta.2007.05.058

5. V. Sastri and J. Perumareddi, Molecular orbital theoretical studies of some organic corrosion inhibitors, Corrosion, 1997, 53, 617-622. doi: 10.5006/1.3290294

6. A. Khramov, N. Voevodin, V. Balbyshev and M. Donley, Hybrid organo-ceramic corrosion protection coatings with encapsulated organic corrosion inhibitors, Thin Solid Films, 2004, 447, 549-557. doi: 10.1016/j.tsf.2003.07.016

7. R.D. Salim, Q.A. Jawad, K.S. Ridah, L.M. Shaker, A.A. Al-Amiery, A.A.H. Kadhum and M.S. Takriff, Corrosion inhibition of thiadiazole derivative for mild steel in hydrochloric acid solution, Int. J. Corros. Scale Inhib., 2020, 9, no. 2, 550-561. doi: 10.17675/2305-6894-2020-9-2-10

8. S.A. Umoren and U.M. Eduok, Application of carbohydrate polymers as corrosion inhibitors for metal substrates in different media: a review, Carbohydr. Polym., 2016, 140, 314-341. doi: 10.1016/j.carbpol.2015.12.038

9. C. Verma, M.A. Quraishi, K. Kluza, M. Makowska-Janusik, L.O. Olasunkanmi and E.E. Ebenso, Corrosion inhibition of mild steel in $1 \mathrm{M} \mathrm{HCl}$ by D-glucose derivatives of dihydropyrido [2, 3-d: 6, 5-d'] dipyrimidine-2, 4, 6, 8 (1H, 3H, 5H, 7H)-tetraone, Sci. Rep., 2017, 7, 1-17. doi: 10.1038/srep44432 
10. R.J. Tuama, M.E. Al-Dokheily and M.N. Khalaf, Recycling and evaluation of poly (ethylene terephthalate) waste as effective corrosion inhibitors for C-steel material in acidic media, Int. J. Corros. Scale Inhib., 2020, 9, no. 2, 427-445. doi: 10.17675/23056894-2020-9-2-3

11. A. Nikitasari, G.P. Sundjono and A. Royani, Polyphosphate performance for inhibiting corrosion of heat exchanger materials, Int. J. Corros. Scale Inhib., 2020, 9, no. 2, 745756. doi: 10.17675/2305-6894-2020-9-2-22

12. S. Umoren, E. Ebenso, P. Okafor and O. Ogbobe, Water-soluble polymers as corrosion inhibitors, Pigm. Resin Technol., 2006, 35, 346-352. doi: 10.1108/03699420610711353

13. S. Umoren and M. Solomon, Recent developments on the use of polymers as corrosion inhibitors - a review, Open Mater. Sci. J., 2014, 8, 39-54. doi: $\underline{10.2174 / 1874088 X 01408010039}$

14. S. Umoren, Polymers as corrosion inhibitors for metals in different media - A review, Open Corros. J., 2009, 2, 175-188. doi: 10.2174/1876503300902010175

15. D.E. Arthur, A. Jonathan, P.O. Ameh and C. Anya, A review on the assessment of polymeric materials used as corrosion inhibitor of metals and alloys, Int. J. Ind. Chem., 2013, 4, 1-9. doi: 10.1186/2228-5547-4-2

16. A. El-Ghaffar, A.M. Baraka, M.M. Hefny, E.A. Youssef and M.M. Aly, Boron Phosphate/Poly (p-phenylenediamine) as a Corrosion Inhibitive System for Steel Protection, Egypt. J. Chem, 2018, 61, 759-771. doi: 10.21608/EJCHEM.2018.4184.1373

17. A. Rajaseka $\mathrm{r}$ and Y.-P. Ting, Inhibition of biocorrosion of aluminum 2024 aeronautical alloy by conductive ladder polymer poly (o-phenylenediamine), Ind. Eng. Chem. Res., 2011, 50, 2040-2046. doi: 10.1021/ie101678x

18. C. Shanmugham and N. Rajendran, Poly (m-phenylenediamine)-coated 316L SS: A promising material for bipolar plates in PEMFC environment, Mater. Corros., 2019, 70, 1646-1656. doi: 10.1002/maco.201810524

19. M. Düdükcü, The electrochemical synthesis of poly (o-phenylenediamine) on stainless steel and its corrosion protection ability in $3.5 \% \mathrm{NaCl}$ solution, Res. Chem. Intermed., 2013, 39, 3641-3647. doi: 10.1007/s11164-012-0868-3

20. P. Manivel, S. Sathiyanarayanan and G. Venkatachari, Synthesis of poly (p-phenylene diamine) and its corrosion inhibition effect on iron in $1 \mathrm{M} \mathrm{HCl,} \mathrm{J.} \mathrm{Appl.} \mathrm{Polym.} \mathrm{Sci.,} \mathrm{2008,}$ 110, 2807-2814. doi: $10.1002 / a p p .28772$

21. S. Abd El Rehim, S. Sayyah and R. Azooz, Poly (p-Phenylenediamine) as an Inhibitor for Mild Steel in Hydrochloric Acid Medium, Port. Electrochim. Acta, 2012, 30, 67-80. doi: 10.4152/pea.201201067

22. S. Abd El Rehim, S. Sayyah, M. El-Deeb, S. Kamal and R. Azooz, Poly (ophenylenediamine) as an inhibitor of mild steel corrosion in $\mathrm{HCl}$ solution, Mater. Chem. Phys., 2010, 123, 20-27. doi: 10.1016/j.matchemphys.2010.02.069 
23. P. Muthirulan, N. Kannan and M. Meenakshisundaram, Synthesis and corrosion protection properties of poly (o-phenylenediamine) nanofibers, J. Adv. Res., 2013, 4, 385-392. doi: 10.1016/j.jare.2012.07.007

24. L.F. D'Elia, R.L. Ortíz, O. Marquez, J. Marquez and Y. Martinez, Electrochemical deposition of poly (o-phenylenediamine) films on type 304 stainless steel, $J$. Electrochem. Soc., 2001, 148, C297. doi: 10.1149/1.1354619

25. P. Muthirulan and N. Rajendran, Poly (o-phenylenediamine) coatings on mild steel: electrosynthesis, characterization and its corrosion protection ability in acid medium, Surf. Coat. Technol., 2012, 206, 2072-2078. doi: 10.1016/j.surfcoat.2011.09.008

26. J.-W. Zhang, Y. Li, Y.-S. Ding, K.-F. Pan and Q. Zhao, Coatings corrosion resistance of poly (o-phenylenediamine) on mild steel in $3.5 \% \mathrm{NaCl}$ : Influence of inorganic acid, $A d v$. Surf. Eng., 2020, 72, 4288-4295. doi: 10.1007/s11837-019-03851-8

27. M. Cui, S. Ren, J. Pu, Y. Wang, H. Zhao and L. Wang, Poly (o-phenylenediamine) modified graphene toward the reinforcement in corrosion protection of epoxy coatings, Corros. Sci., 2019, 159, 108131. doi: 10.1016/j.corsci.2019.108131

28. E.N. Zare, M.M. Lakouraj, S. Ghasemi and E. Moosavi, Emulsion polymerization for the fabrication of poly (o-phenylenediamine) @ multi-walled carbon nanotubes nanocomposites: characterization and their application in the corrosion protection of 316L SS, RSC Adv., 2015, 5, 68788-68795. doi: 10.1039/C5RA11295H

29. C. Zhou, C. Zhou and J. Zhang, Investigation of corrosion resistance of poly (ophenylenediamine)-ZnO composites on stainless steel, Int. J. Electrochem. Sci., 2019, 14, 8173-8184. doi: 10.20944/preprints201812.0141.v1

30. A. Ganash, Anticorrosive properties of poly (o-phenylenediamine)/ZnO nanocomposites coated stainless steel, J. Nanomater., 2014, 1-8. doi: 10.1155/2014/540276

31. C. Zhou, C. Zhou and J. Zhang, Investigation of Corrosion Resistance of poly (ophenylenediamine)-ZnO Composites on Carbon Steel, Preprints, 2018, 120-141. doi: 10.20944/preprints201812.0141.v1

32. C. Chen, S. Qiu, S. Qin, G. Yan, H. Zhao and L. Wang, Anticorrosion performance of epoxy coating containing reactive poly (o-phenylenediamine) nanoparticles, Int. J. Electrochem. Sci., 2017, 12, 3417-3431. doi: 10.20964/2017.04.47

33. T. Siva, K. Kamaraj and S. Sathiyanarayanan, Electrosynthesis of poly (aniline-co-ophenylenediamine) film on steel and its corrosion protection performance, Prog. Org. Coat., 2014, 77, 1807-1815. doi: 10.1016/j.porgcoat.2014.06.003 